\title{
Photoflash and Laser Ignition of Select High-Nitrogen Materials
}

\author{
N. N. De ${ }^{1 \S}$, N. R. Cummock ${ }^{1}$, I. E. Gunduz ${ }^{1}$, B. C. Tappan ${ }^{2}$ and S. F. Son ${ }^{1}$ \\ ${ }^{1}$ Purdue University, West Lafayette, IN 47907 \\ ${ }^{2}$ Los Alamos National Laboratory, Los Alamos, NM 87545 \\ §nde@purdue.edu, Phone: +1 817-944-8969
}

\begin{abstract}
Gas-producing energetic materials that can be readily ignited with a photoflash are typically opaque sensitive primary explosives. In this study, we explore the photoactivity of select highnitrogen (HiN) compounds that are much less sensitive than primary explosives. These HiN materials produce large amounts of gas upon decomposition and this makes them suitable for use in actuators, igniters, or micro-thrusters. This paper presents ignition experimental results using similar shaped pulses at two different wavelengths; specifically using a xenon photoflash and a single wavelength $\mathrm{CO}_{2}$ laser. Several select HiN materials were tested for flash ignitability, and those that were found to be flash ignitable were further ignited with $\mathrm{CO}_{2}$ laser heating. By comparing ignition behavior at various laser and flash intensities, some ignition mechanisms are suggested. Thermal heating, regardless of source, appears to be the dominant mechanism responsible for ignition and photochemical effects appear to be negligible in the ignition of the materials considered in this study. Higher laser and photoflash irradiance is shown to require less energy, and is therefore more efficient. The opacity of the material is an important consideration in ignitability, but not a sufficient criteria. We find that opaque materials that successfully propagate well in small capillary tubes are also more likely to successfully flash ignite. We suggest this is due to the higher burning rate of these materials and also in part due to the exothermic reaction occurring at or near the burning surface, allowing the reactions to proceed without quenching.
\end{abstract}

Keywords: high-nitrogen energetic materials, flash ignition, laser ignition, photochemical effects, photoactivity, non-contact ignition, gas generators 


\section{NOMENCLATURE}

$\begin{array}{ll}I_{\text {peak }} & \text { Peak irradiance } \\ E^{\prime \prime} & \text { Energy flux deposited per unit area } \\ d & \text { Diameter } \\ A_{p} & \text { Wall area } \\ V & \text { Volume } \\ \delta & \text { Flame thickness } \\ \dot{q}_{c o n d}^{\prime \prime} & \text { Rate of heat conduction per unit area } \\ \dot{q}_{c h e m}^{\prime \prime} & \text { Rate of heat generation per unit volume } \\ T & \text { Temperature } \\ \frac{d \varepsilon}{d t} & \text { Reaction rate, } \varepsilon \text { is the reaction progress variable } \\ k_{g} & \text { Gas phase thermal conductivity } \\ \rho & \text { Density } \\ \alpha_{g} & \text { Gas phase thermal diffusivity } \\ r_{b} & \text { Burning rate } \\ r & \text { Reflectivity } \\ Q & \text { Heat release per unit mass } \\ C_{p} & \text { Heat capacity } \\ m & \text { Mass }\end{array}$

\section{Introduction}

Remote, non-contact ignition of energetic materials, especially gas producing secondary explosives would have a wide variety of possible applications. Most photoflash-ignitable gas generating energetic materials that have been considered are primary explosives, such as azides and fulminates [1]; the sensitivity of these materials limits their applications. Secondary explosives that could be photoflash ignited may find use in a wider variety of applications such as igniters, gas generators in micro-thrusters and micro-actuators for microscale devices. 
Some researchers have attempted to make gas generating secondary explosives photosensitive through the use of additives. One such attempt has been to add photosensitive carbon nanotubes into gas generating energetic materials, such as pentaerythritol tetranitrate (PETN), to create a flash ignitable mixture [2]. In part because it is a clear crystal, PETN will not flash ignite on its own. However, these flash ignitable PETN mixtures may have unacceptably high sensitivity for some non-explosive applications and the use of carbon nanotubes and other additives could introduce uncertainty from batch to batch in processing and formulation. Such additives could also make the mixture less efficient and more fuel rich, possibly increasing the likelihood of a secondary reaction with air. Since the combustion products could be inhaled in many applications, avoiding any additives such as carbon nanotubes and metals is desired. Hence, a single compound that is flash ignitable, gas generating, and has acceptable sensitivity (not detonable) is desirable.

\section{$\underline{1.1 \text { Ignition by Irradiation }}$}

Non-contact ignition mechanisms can involve a wide range of electromagnetic radiation including visible light, infrared radiation (IR), microwaves, or even ionizing radiation. Research into ignition of explosives by radiation dates back to the 1950s. Eggert et al. published studies on the ignition of azides, acetylides, fulminates and perchlorates; detonations were also observed for some explosives under sufficiently high radiation intensities [3]. As far back as 1955, Nelson et al. discussed how heterogeneous flash ignition (ignition of a mixture of different substances, in this case in a mixture of fine light absorbing metallic particles suspended in polyethylene) could result in very high but localized temperatures that can initiate reactions [4]. Early studies were also carried out by Bowden and Yoffee, who studied photodecomposition (direct decomposition of chemicals by absorption of light) of azides, nitrides, fulminates and perchlorates [1]. They also explored the photosensitization of silver azide by dyes and gold particles [1].

More recently, research into photoflash ignition of different explosive mixtures, with a wide variety of additives, have been carried out [2]. Single-walled carbon nanotubes (SWNTs) have been extensively studied because of their high absorptivity and their unique ignition behavior when irradiated with a photoflash $[5,6,7]$. As discussed above, Maana et al. demonstrated that single wall carbon nanotubes mixed with PETN could ignite at remarkably low flash irradiance 
[2]. Braidy et al. experimentally showed that iron (Fe) nanoparticles embedded in SWNTs will flash ignite to produce oxides of iron [8]. Carbon nanotubes have also been added to fuel/air mixtures to allow for photoflash ignition [9]. However metals and carbon nanotube additives may be undesirably toxic for some applications so alternatives are of interest.

High energy ball milling has also been shown to produce flash ignitable energetic materials. When micron size aluminum particles and poly-carbon monofluoride (PMF) are mechanically activated via high-energy ball milling, the resulting Al/PMF composite particles are ignitable by an optical flash [10]. This is thought to be due to the nanoscale features produced in the milling process, similar to what is observed with nanoscale aluminum. Other additives considered to make explosives more sensitive to ignition by photoflash and lasers include gold and silver nanoparticles $[11,12]$.

Non-thermal ignition mechanisms for photoflash ignition have been hypothesized. Such mechanisms can involve direct photoexcitation of electrons within molecules at only certain wavelengths of light, which get preferentially absorbed [13]. This photothermal effect can directly lead to chemical breakup or the energy can degrade to heat [13]. Abboud et al. suggests that localized surface plasmon resonance enhances heating in flash irradiated aluminum nanoparticles (nAl), which in turn leads to ignition [14]. Greenfield et al. examined the photoactivity of a tetrazine derivatives of PETN known as pentaerythritol trinitrate chlorotetrazine (PetrinTzCl) [15]. The derivative PetrinTzCl exhibited a much higher level of photoactivity than PETN when irradiated with a $532 \mathrm{~nm}$ wavelength laser. It was reasoned that since tetrazine has a high heat of formation and is a good chromophore (can contribute to color, and hence absorption in the visible spectrum), tetrazine derivatives such as PetrinTzCl could possibly display direct photochemical decomposition under visible light. Other researchers reported on the photoactivity of nanoparticles of gold and other metals to UV and visible radiation due to plasmon resonance, with potential applications in engineering of metals and semiconductors [11]. Flash irradiation has also been researched as a cheap, chemical-free method for the deoxygenation reaction of graphite oxide in the bulk production of graphene based materials [16]. It is theorized that the flash creates strong photothermal and photoacoustic effects in order to start the decomposition [16]. 


\section{$\underline{1.2 \text { High-Nitrogen Compounds }}$}

High-nitrogen (HiN) materials are a class of energetic compounds that derive most of their energy from the high positive heat of formation, released by decomposition, rather than from oxidation reactions of carbon or hydrogen, as is the case with most other energetic materials [17]. HiN materials usually contain significant amounts of nitrogen in their molecular structure, and release large amounts of gaseous nitrogen upon decomposition, along with other gases like hydrogen [18]. With a few notable exceptions such as azides, hydrazines and tetrazines, HiN compounds are usually aromatic heterocyclic compounds with a wide variety of substituents. Research into HiN materials dates back to the late 1800 s, followed by research on tetrazine and tetrazole rings by the 1950s and 1960s. Over the decades, a number of new (mostly nitrogen) derivatives based on these rings and other new structures have been synthesized and tested [19, $20,21]$.

Derivatives of the tetrazine and tetrazole rings are among the most important HiN materials that have been studied. These include 6,6-bis(1H-1,2,3,4-tetrazole-5-ylamino)-s-tetrazine (BTATz), 3,6-dihydrazino-1,2,4,5-tetrazine (DHT) and mixed N-oxides of 3,3'-zeo-bis(6-amino-1,2,4,5tetrazine) $[22,18]$. The tetrazole and tetrazine ring and their high nitrogen derivatives yield relatively clean and less toxic products $[23,24]$. DAATO3.5, which is an N-oxide of 3,3'-zeobis(6-amino-1,2,4,5-tetrazine) has one of the highest burning rates of organic compounds. Azides, which are molecules containing the azide $\mathrm{R}-\mathrm{N}_{3}$ functionality or salts with the $\left(\mathrm{N}_{3}^{-}\right)$anion, are widely used HiN materials and have been used as airbag gas generators and as detonators. However, many azides are primary explosives. Another class of HiN materials consists of furazan derivatives of 3,4-diaminofurazan (which was first synthesized in 1968). One of these

derivatives includes 3,3'-diamino-4,4'-azoxyfurazan (DAAF). Figures 1 and 2 show the molecular structure of two important HiN materials, BTATz and DAATO3.5. 


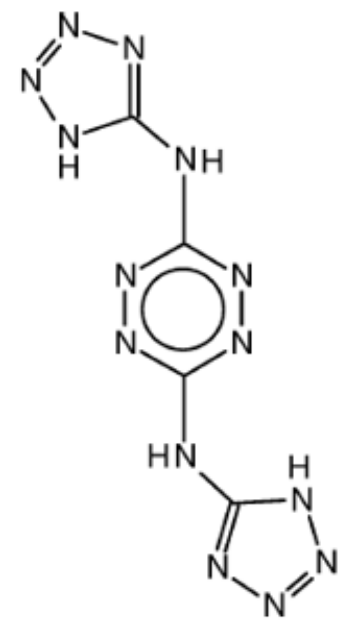

Figure 1: BTATz molecule [22].<smiles></smiles>

\section{$a+b+c+d+e=3.5$}

Figure 2: DAATO3.5 molecule [22].

A wide variety of HiN materials are synthesized by multistep routes that involve different substitute groups added to traditional aromatic rings such as the tetrazine and tetrazole ring. HiN materials such as DHT, BTATz and DAATO3.5 are all examples of such compounds. There is active research into synthesis of new HiN compounds for specific applications. Chavez et al. have studied several HiN compounds and published on the synthesis route of nitroguanyl substitutes to the tetrazine rings [21] and of amino derivatives to the tetrazine ring [17]. International research in HiN materials include work by Sivabalan et al. who have studied the decomposition mechanisms of two gas generating HiN materials: hydrazinium azotetrazolate (HAZ) and 1,1' -dinitro-3,3' -azo-1,2,4-triazole (N-DNAT) [25]. 
High-nitrogen (HiN) materials have many interesting and potentially useful properties. These include reasonable insensitivity to electrostatic discharge and friction, high heat of formation, low temperature combustion and fast burning rate in some cases [22]. In addition, most HiN materials can decompose to release a host of relatively non-toxic gaseous compounds containing nitrogen, carbon, hydrogen, and oxygen. In the case of non-azide based HiN materials, most of these gases originate from the elimination of bonds of nitrogen and the loss of other substituent groups attached to a heterocyclic base [26]. Also with the exception of azides, most HiN materials are secondary explosives or otherwise not known to detonate without strong shock initiation. BTATz and TAGzT, for example, have not been shown to be detonable. Through crystal packing, some HiN materials can also store large amounts of hydrogen. For example, triaminoguanidinium azotetrazolate (TAGzT) stores more hydrogen per volume than even liquid hydrogen. Decomposition pathways (different from ignition mechanisms discussed earlier) of different HiN materials can vary significantly. Bhattacharya et al. discussed how derivatives and $\mathrm{N}$-oxides of the tetrazine ring have distinctly different decomposition behavior and intermediate species compared to the bare tetrazine [27]. In the decomposition of tetrazine, nitrogen (N) and hydrogen cyanide $(\mathrm{HCN})$ are produced through a dissociation mechanism while the decomposition of N-oxides of the tetrazine ring, such as DAATO3.5, is different because of the different molecular structure.

Optical ignition of HiN materials could find numerous potential applications. Because of their color (visible opacity), many HiN materials may be more amenable to visible radiation absorption. For energetic materials sensitive to visible light, the color can directly play a role in ignition behavior as suggested in studies. In particular, Bowden and Yoffe showed that optically darker primary explosives have lower ignition thresholds that white (clear) and yellow colored ones [1]. Because of significant gas production, HiN materials could be used as low toxicity gas generators for air-bags, fire suppressants, detonators, fire extinguishers, actuators, microthrusters \& micro-actuators for microscale devices and as fuels in solid and reverse hybrid rocket motors $[22,18,28]$.

There have also been studies in high energy nano-scale energetic materials [29], which have been seen as key to the advances in small scale application of energetics. High-nitrogen materials 
offer much less complexity and potentially less toxicity than metal based nano-scale energetic materials or additives. Unfortunately, studies in remote optical ignition of HiN materials are very limited.

Recently, a few researchers have examined the ignition of HiN materials using laser irradiation. Ali et al. [18] studied the ignition of DHT, DAAF and DAATO3.5 using a $\mathrm{CO}_{2}$ laser. The experimental set-up included a high-speed camera and an IR detector. It is shown that an exponential correlation between ignition delay and irradiance exists. No similar study of photoflash ignition of HiN materials is known to exist.

Besides the work by Ali et al. [22, 18], very few studies have been carried out on the ignition of HiN materials by irradiation, especially in the visible spectral range. This study attempts to fill in many missing gaps in the flash ignition properties of HiN materials.

The main objectives of this study are to:

- Determine which of the considered HiN materials are photoflash ignitable, what the ignition thresholds (lowest irradiance and energy input necessary to ignite these HiN materials) and ignition delays are.

- Determine possible ignition mechanisms by comparing ignition behavior between two different wavelengths using a photoflash and a $\mathrm{CO}_{2}$ laser. 


\section{Experimental Set-up}

\subsection{Flash Ignition Setup and Calibration}

A Nikon SB-24 Xenon photoflash was used to irradiate samples with a short pulse of a broadband light in the visible and near IR range [30, 31, 32]. Figure 3 shows a schematic of the flash ignition set-up. This set-up is consistent with what was used in previous photoflash studies [10]. The only modification made to the photoflash is the removal of two layers of plastic filters, so that there is only one clear glass layer between the flash bulb and the outside air. The photoflash is manually triggered and the light emitted is detected by a fast photodetector (ThorLabs PDA10A). This triggers an oscilloscope to send a TTL pulse to two high speed cameras (Vision Research Phantom V7.3 monochrome and color). Both cameras record at 50,000 frames per second (fps). One camera is set up for schlieren imaging while the other is set up to record a regular video (see Figure 3). The schlieren set-up consists of a light emitting diode, two mirrors, a knife edge and one high speed camera.

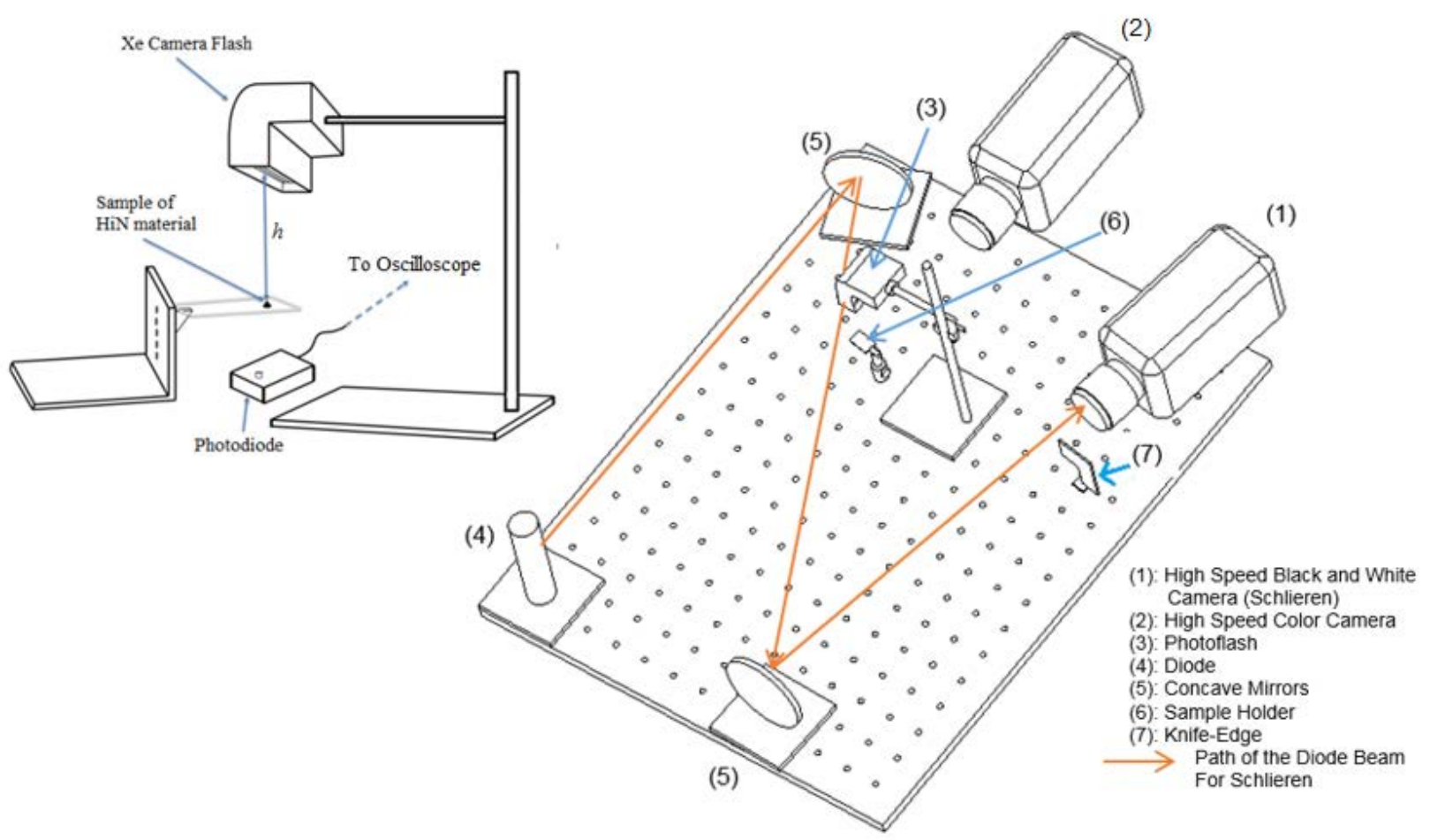

Figure 3: Flash calibration experimental set-up. 
The energy output of the photoflash was measured and calibrated using a method similar to that used by Aslin [33]. This involved using a sample of known mass and heat capacity and flash irradiating the sample at varying distances. The temperature rise in the material was recorded and the heat energy irradiated by the photoflash at different heights above the flash was determined. Thermocouples were carefully placed on the sample at locations where there will be no direct irradiation from the flash. A silver based thermal paste was used to ensure the thermocouples have good contact with the sample. The accuracy of the method depends on high absorptivity, therefore, each sample was coated with soot before testing. The following equation was used in order to determine the energy per unit area outputted by the photoflash,

$$
E^{\prime \prime}=\frac{C_{p} m \Delta T}{A(1-r)}
$$

where $E^{\prime \prime}$ is the energy irradiated per unit area, $C_{p}$ is the heat capacity of the metallic sample, $m$ is the mass of the sample, $\Delta T$ is the temperature rise in the sample, $A$ is the irradiated surface area of the sample, and $r$ is the reflectivity of the irradiated sample. In this work, $r$ was assumed to be close to zero.

Figure 4 shows a plot of energy per unit area measured at varying distances from the photoflash. An inverse square trend with $h$ is observed, where $h$ is the distance between the sample and the photoflash. It is important to note that the magnitude of the values recorded are noticeably higher that those used in previous studies. Because of the large amounts of scatter noted in these experiments, a large number of data points were obtained. Repeatability was verified by changing batteries and experimenting with different samples, each coated with soot and each having different heat capacities to avoid systematic errors. In addition, errors bars were determined for each measurement by taking into account the uncertainty in the mass, heat capacity, temperature measurement and the height from photoflash bulb $(h)$. A thorough discussion on how this was done can be found in the supplemental material section. 


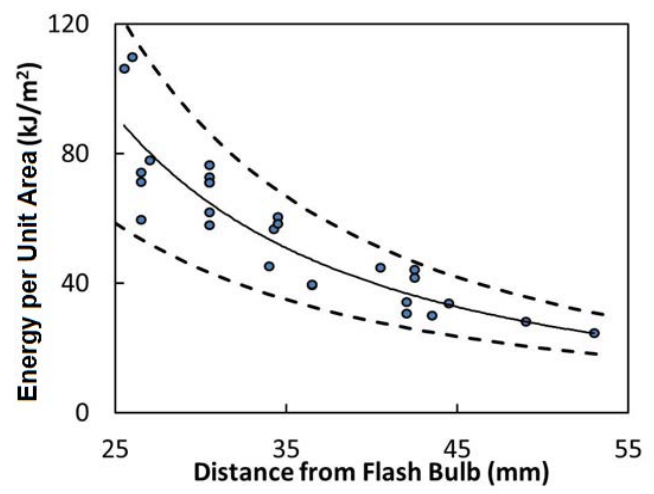

Figure 4: Energy per unit area irradiated by the photoflash (dashed lines are $95 \%$ confidence interval).

The temporal profile of the flash is measured using the photodetector in order to characterize peak flash intensity with time. A neutral density filter was placed between the flash and the measurement device in order to avoid saturation of the photodetector. Figure 5 shows the temporal profile of the photoflash.

The time varying intensity profile (as shown in Figure 5) is directly proportional to the irradiance of the flash; therefore, the profile of the radiant intensity of the photoflash is similar to Figure 5. This profile could be integrated and the outcome would give the energy output of the flash,

$$
E^{\prime \prime}(h)=I_{\text {peak }}(h) \times \int_{0}^{\sim 7 m s} I(t) d t
$$

By normalizing this profile and integrating the flash intensity over time, a constant multiple, $\int_{0}^{\sim 7 m s} I(t) d t$, was found which related the voltage output from the photodetector to the energy output of the flash bulb. Through this method, a peak irradiance $\left(I_{\text {peak }}\right)$ could be determined at different stand-off distances for this flash bulb. 


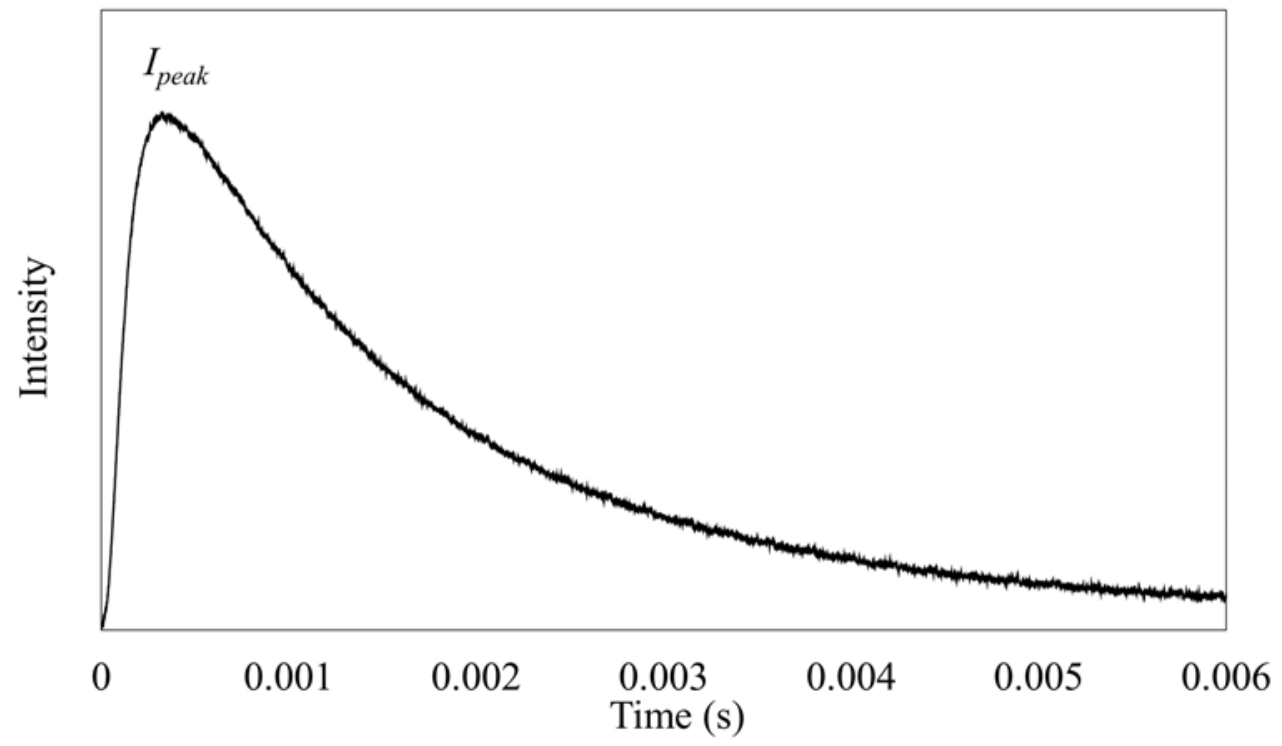

Figure 5: Temporal profile of flash.

\section{$\underline{2.2 \text { Laser Ignition Set-up and Calibration }}$}

The $\mathrm{CO}_{2}$ laser (Coherent GEM 100A) setup is shown in Figure 6, The $\mathrm{CO}_{2}$ laser wavelength is $10.6 \mu \mathrm{m}$. The beam is directed to the sample through a series of mirrors and is focused with a $\mathrm{ZnSe}$ lens with a focal length of $50 \mathrm{~cm}$. A window that reflects $2 \%$ of incident laser is used to direct a small fraction of the laser energy to a beam sampler, which is used to monitor the timing of the laser pulse. The $\mathrm{CO}_{2}$ laser is controlled by LabVIEW, and an arbitrary pulse shape and duration can be programmed. A truncated sinusoidal wave (Figure 7) with a frequency of $44.5 \mathrm{~Hz}$, offset by 180 degrees and with a signal duration of 6 milliseconds produces a pulse shape that was used to approximate the flash pulse profile. The total area under both the flash and the laser profiles (corresponding to the total energy per unit area) is approximately the same when the peak irradiance of each profile is equal. This is done to compare the ignition behavior of the HiN materials subjected to two similar profiles; one with a broadband photoflash and another with a laser that irradiates in far-IR spectrum. 


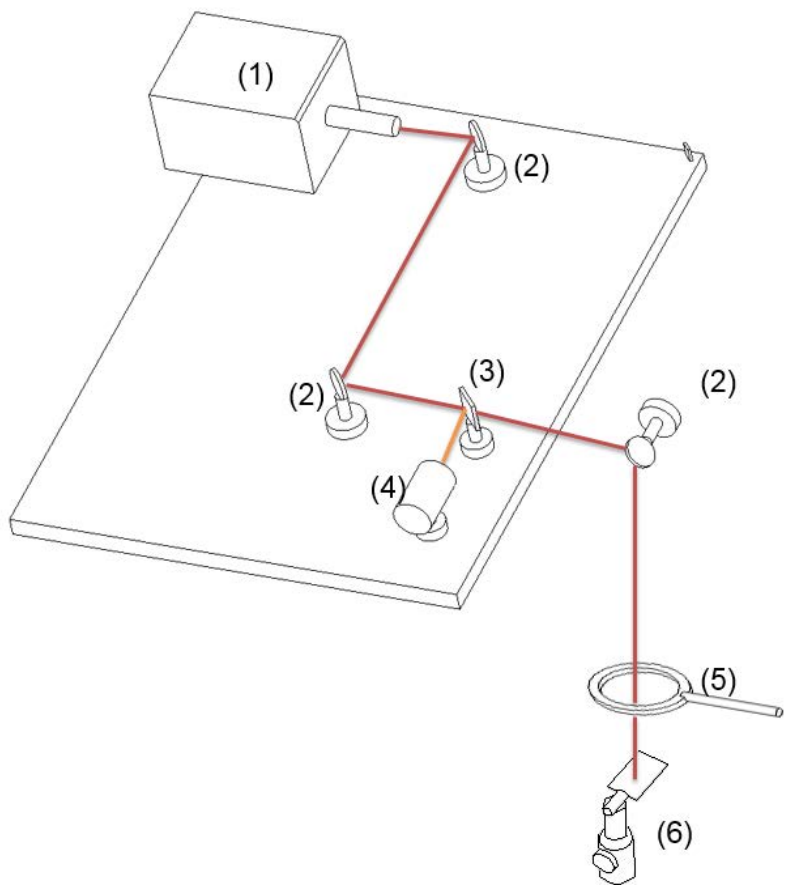
(1): $\mathrm{CO}_{2}$ Laser
(2): Turning Mirror
(3): $2 \%$ Reflecting Window
(4): Beam Sampler
(5): Focusing Lens
(6): Sample Holder

Figure 6: $\mathrm{CO}_{2}$ laser set-up.

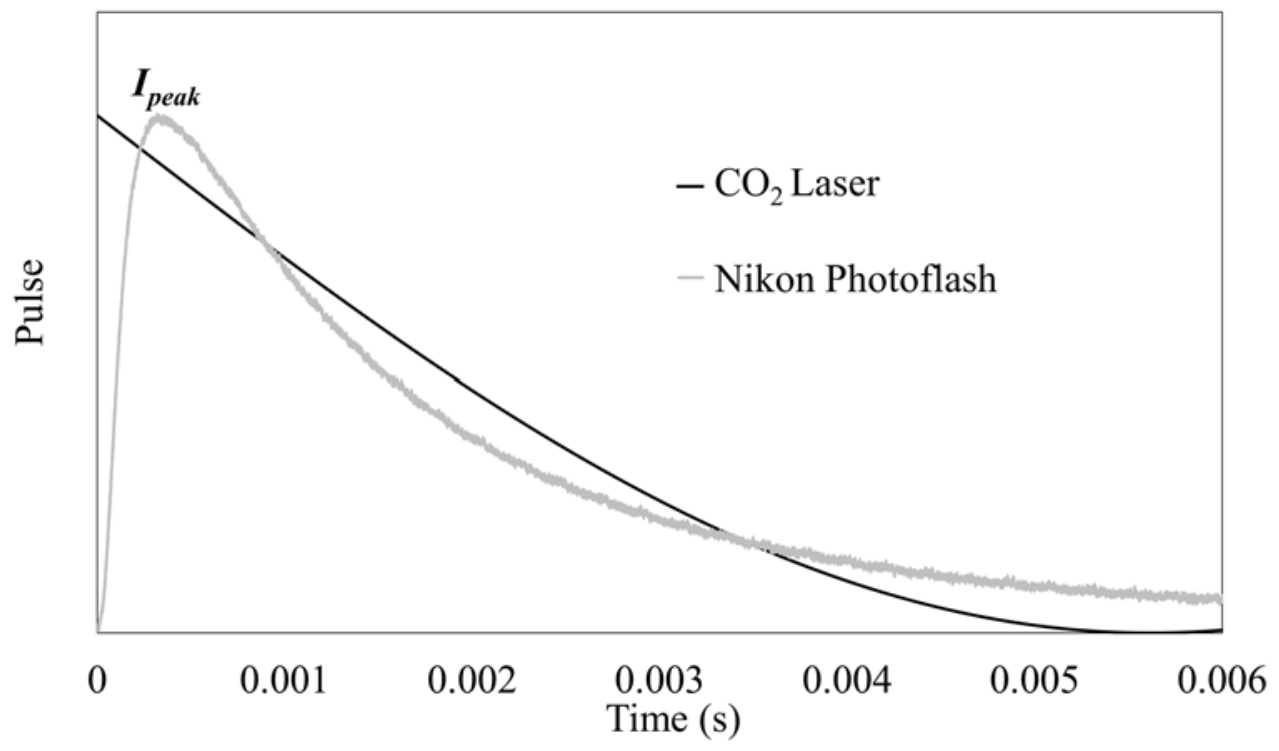

Figure 7: Flash and $\mathrm{CO}_{2}$ laser comparison.

The peak intensity is directly related to the amplitude of the pulse profile inputted in LabVIEW. A thermopile based power meter (Coherent LM-200 HTD Laser Power Detector) is used to measure the power output of the $\mathrm{CO}_{2}$ laser. The peak irradiance can be calculated using the measured power output and the laser spot size. The spot size was determined in previous 
experiments using the power meter and a knife edge. The laser outputs a Gaussian spatial profile and the edge of the spot size is defined by the radial distance from the beam center to where the irradiance drops to $1 / \mathrm{e}^{2}$ of the peak irradiance. The peak irradiance is located at the center of the laser beam. For both the BTATz and DAATO laser ignition tests, the spot size was mostly set at $1.826 \mathrm{~mm}$ or $2.034 \mathrm{~mm}$ in diameter while some ignition events at higher irradiances were carried out with a spot size of $1.306 \mathrm{~mm}$.

Similar to the flash setup, high-speed color video (using the color Phantom V7.3) is used for direct visual observations of the igniting particles while the monochrome Phantom is used for schlieren imaging. For the laser experiment, both cameras are triggered by a TTL signal originating from the $\mathrm{CO}_{2}$ laser controller.

For each material, tests are selected at incremental levels which span a range of laser irradiance levels at which ignition does not occur and those that ignition occurs. Once a bound for ignition is determined, a bisection method is used to narrow down the range in which the threshold lies. This process is continued until the uncertainty in the laser power is as large as the bound between the two power settings, the average of which is the ignition threshold. Samples used are all smaller than the spot size of the laser. The small sizes of samples were necessary for two reasons: because of the small spot size of the lasers and also because of the limited amounts of samples available.

\section{$\underline{2.3 \text { Calculation of Ignition Delay and Ignition Energy }}$}

The HiN materials decompose and gasify with very little light emission. Hence, ignition delays were determined using schlieren imaging. The ignition delay is the time from the trigger to the first visible onset of gasification. The ignition delay is subsequently used to determine the total energy irradiated prior to ignition, as shown in Figure 8. Determining the energy irradiated prior to ignition (called the ignition energy) is useful in comparing the flash and laser ignition energy thresholds. 


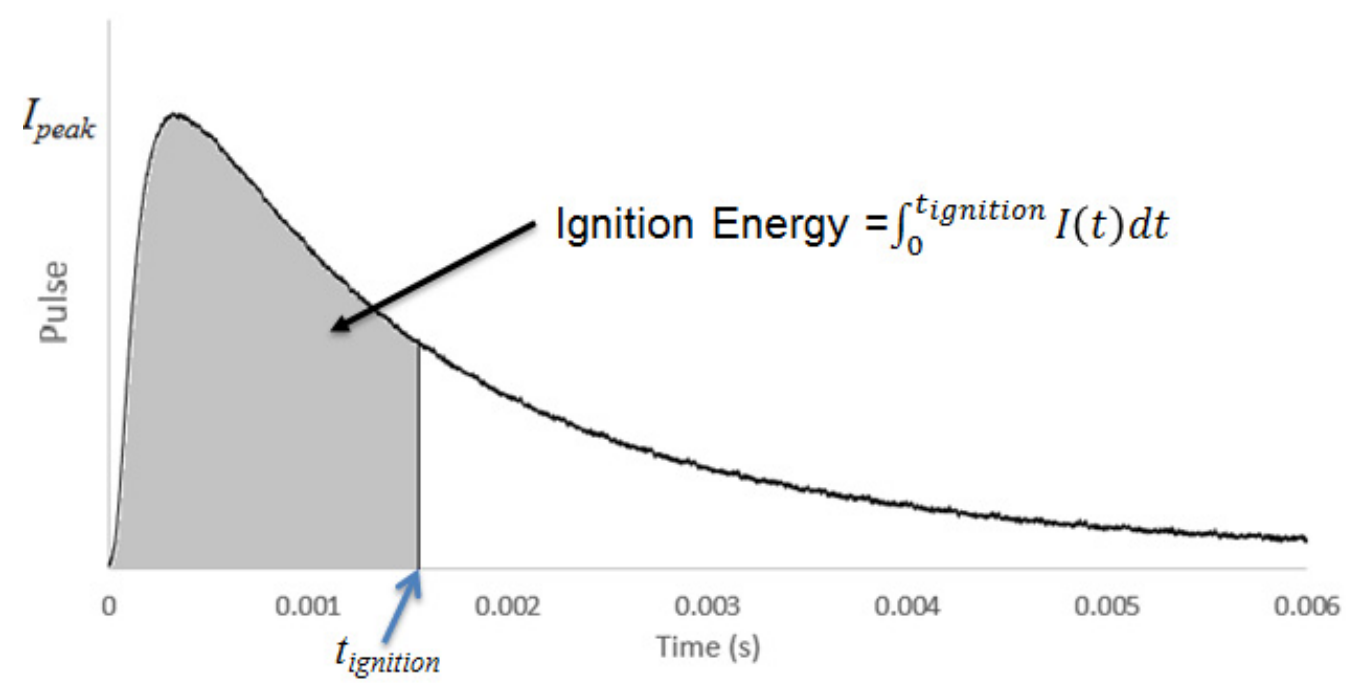

Figure 8: Ignition energy is the total energy irradiated prior to ignition.

\subsection{Microchannel Combustion Experiments}

In order to determine how HiN materials deflagrate in small channels, samples of the HiN materials were packed in capillary tubes and ignited. This is in line with prior work [34]. Samples were loaded into capillary tubes (made from quartz glass with a $0.05 \mathrm{~mm}$ wall thickness) and compacted. $\mathrm{A} \mathrm{CO}_{2}$ laser was used to ignite the sample at the tip of the capillary tubes. Videos of the propagation and/or quenching of the flame through the capillary tube were recorded with a Phantom Miro 4 high speed camera.

\section{Results and Discussion}

\section{$\underline{3.1 \text { Flash Ignitability of HiN materials }}$}

As seen in Table 1, not all HiN materials flash ignited. Of the five HiN materials tested, only two, BTATz and DAATO3.5, flash ignited for the conditions considered. Reactivity is expected to play a role in successful flash ignition. Consequently, as a comparison, the DSC onset temperatures of exothermic reactions for these materials are also included in Table 1. No correlation is apparent between DSC onset temperature and flash ignitability. Although DAATO3.5 has the lowest DSC onset temperature and BTATz has the highest, both could be flash ignited. This is not surprising since DSC threshold temperature trends often do not 
correspond to ignition threshold trends measured at significantly different heating rates, although sometimes they might be consistent in at least the trend. These results further corroborate that rate dependent factors can lead to different trends.

TKX-50 is a white transparent crystal powder and scatters visible light. Consequently, it is possible that it did not flash ignite due to its low absorption at the flash wavelengths. In Table 2 we summarize the ignition experiments performed on those HiN that flash ignited. The range of flash irradiances reflect the span from the lowest to the highest ignition irradiances in the entire study. The flash irradiances are changed by carefully varying the height of the sample from the bulb of the photoflash.

Table 1: Flash Ignitability of Samples

\begin{tabular}{cccc}
\hline Compound & Observed Color & DSC onset $\left({ }^{\circ} \mathrm{C}\right)$ & Flash Ignitable \\
\hline BTATz & Orange [35] & 264 & Yes \\
DAATO3.5 & Dark Maroon [18] & 177 & Yes \\
DAAF & Orange [36] & 256 & No \\
TKX-50 & White [37] & 222 & No \\
TAGzT & Yellow [35] & 195 & No \\
\hline
\end{tabular}

Table 2: Summary of Flash Experiments for BTATz and DAATO3.5

\begin{tabular}{ccc}
\hline Material Tested & $\begin{array}{c}\text { Flash Irradiance } \\
\left(I_{\text {peak }}\right) \text { Range } \\
\text { W/cm }\end{array}$ & $\begin{array}{c}\text { Total Number } \\
\text { of Flash Tests }\end{array}$ \\
\hline BTATz & $2800-8050$ & 35 \\
DAATO3.5 & $1500-6150$ & 25 \\
\hline
\end{tabular}

Figure 9 and Figure 10 show still images from the flash ignition test. Scattering of unreacted particles was observed in both the laser and flash ignition (as seen in the images presented). This particle ejection is due to the rapid gasification of only a portion of the sample. The expanding 
gas generated causes unreacted sample to be pushed outward as some particles ignite sooner than others.
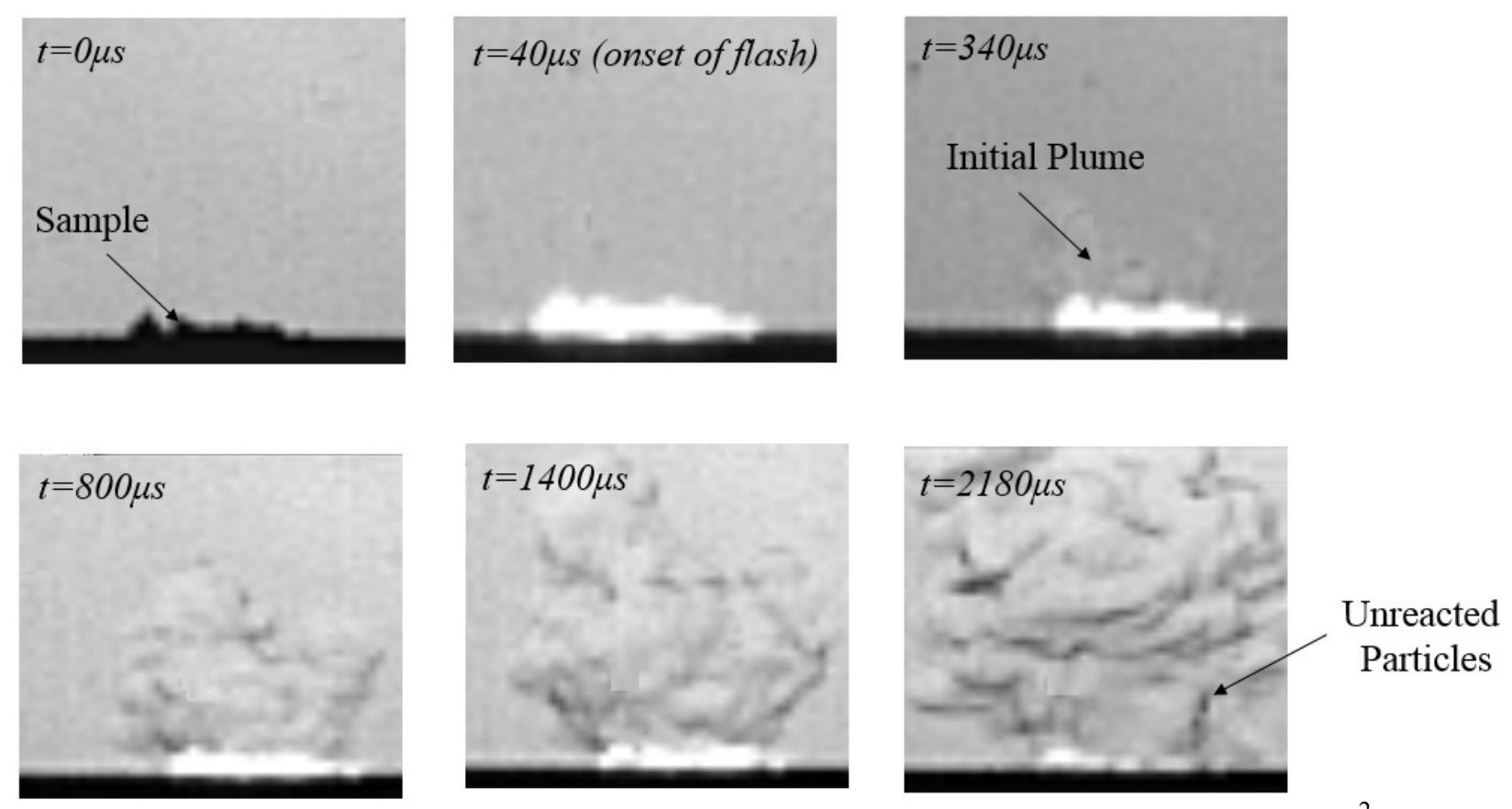

Figure 9: Schlieren sequence during flash ignition of BTATz $\left(I_{\text {peak }}=3730 \mathrm{~W} / \mathrm{cm}^{2}\right)$.
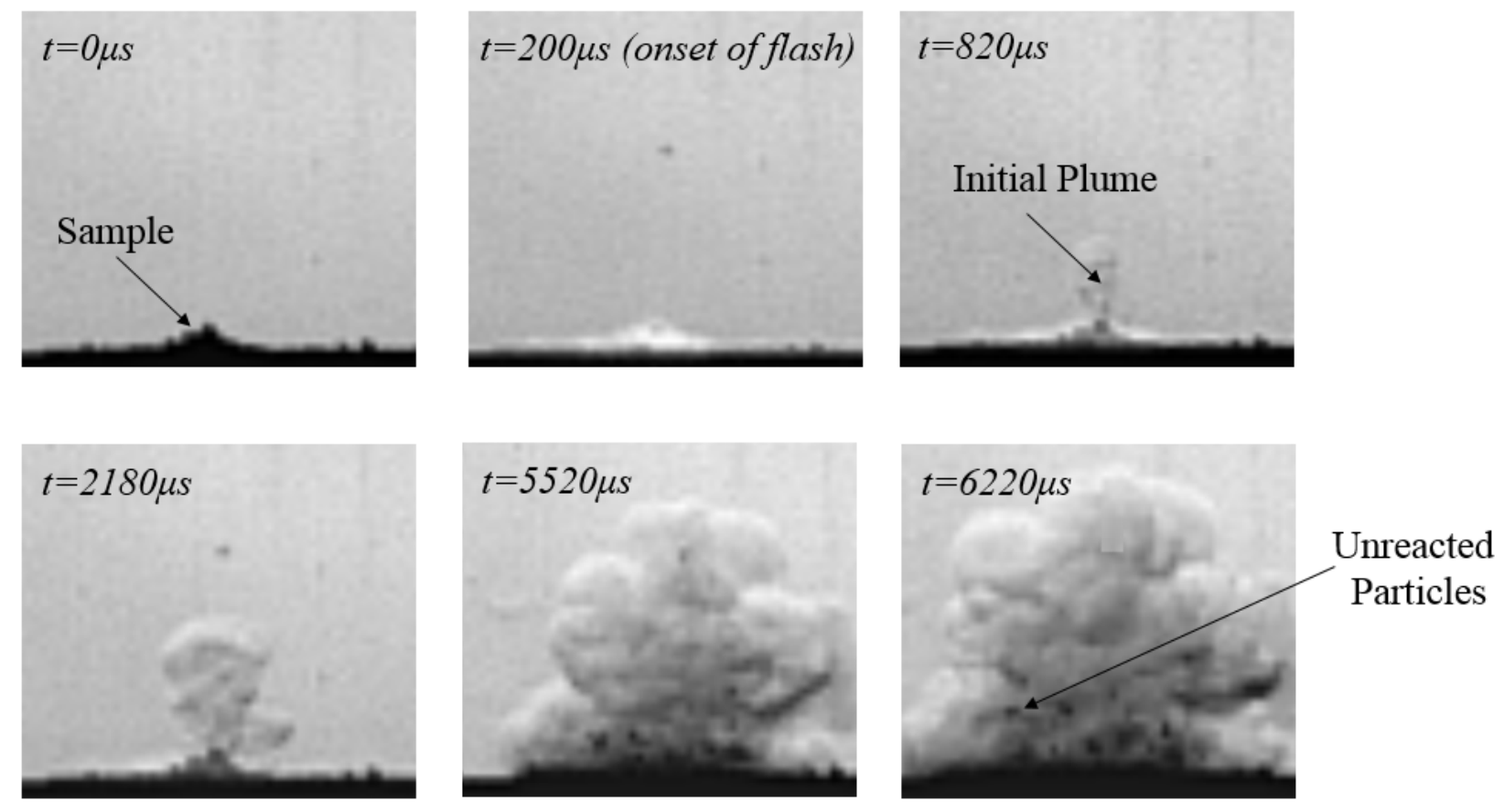

Figure 10: Schlieren sequence during flash ignition of DAATO 3.5 (at $I_{\text {peak }}=1530 \mathrm{~W} / \mathrm{cm}^{2}$ ). 


\subsection{Microchannel Combustion Experiment}

In previous studies with DAATO3.5 and BTATz, it was observed that these two HiN materials can successfully propagate through very small diameters [34], but other HiN materials were not reported. Therefore, BTATz, DAAF, TAGzT and DAATO3.5 were tested in the capillary tube experiment as described in the experimental set-up.

The capillary tube results correlate with the flash ignition results in that the same two materials that successfully flash ignited can also deflagrate in the capillary tubes. Only DAATO3.5 and BTATz successfully propagated in these tubes. A simple model is used to explain some of the contributing factors of quenching in small channels. Figure 11 shows a schematic of a flame in a small channel.

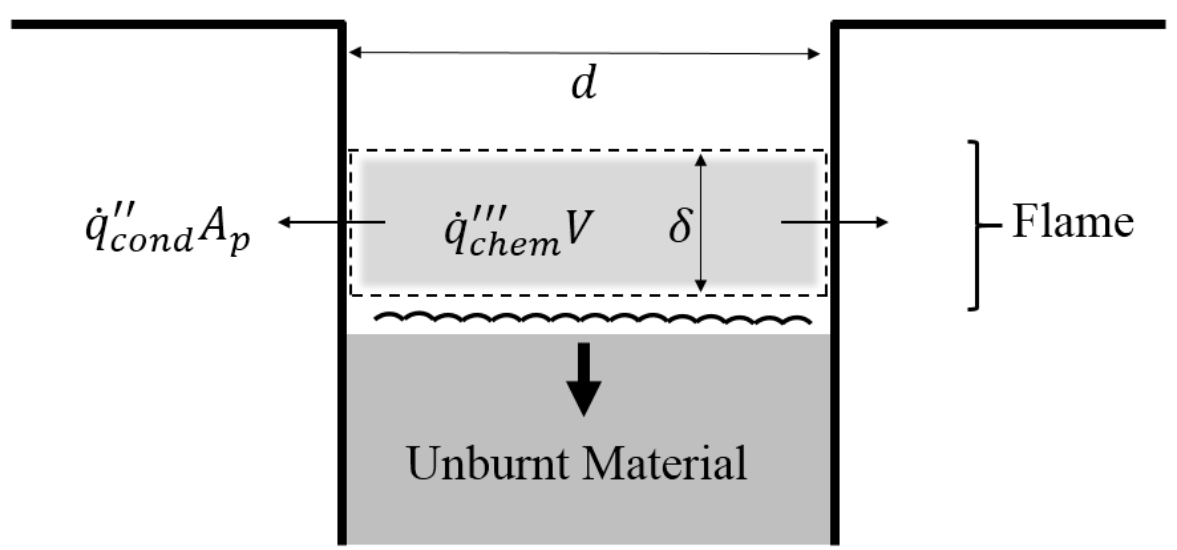

Figure 11: Propagation of a flame through a capillary tube.

Successful propagation of a flame in a capillary tube requires the heat from the chemical reaction to overcome heat losses to the walls and ignite unburnt materials. Based on Figure 11, a simple heat balance is derived to determine a critical diameter for combustion, $d$ at which the flame will quench,

$$
\dot{q}_{c h e m}^{\prime \prime \prime} V=\dot{q}_{c o n d}^{\prime \prime} A_{p},
$$

where $V$ and $A_{p}$ are the flame volume and wall area in contact with the flame, $\dot{q}_{c h e m}^{\prime \prime \prime}$ is the heat generated per unit volume and $\dot{q}_{c o n d}^{\prime \prime}$ is the heat conducted through the wall per unit area. Assuming Fourier conduction at the wall and a simple model for the heat release, we can write, 


$$
\dot{q}_{\text {chem }}^{\prime \prime \prime}=\frac{d \varepsilon}{d t} Q \rho .
$$

With $\rho$ (density), $Q$ (heat release per unit mass), $\varepsilon$ (reaction progress variable) and $k_{g}$ (gas phase thermal conductivity); substituting into Eq. (3),

$$
\frac{d \varepsilon}{d t} Q \rho \frac{\pi \delta d^{2}}{4}=k_{g}\left[\frac{d T}{d x}\right]_{\text {wall }} \pi d \delta \text { or } \frac{1}{4} \frac{d \varepsilon}{d t} Q \rho d=k_{g}\left[\frac{d T}{d x}\right]_{\text {wall }} .
$$

The lower bound for the gradient at the wall is: $\left[\frac{d T}{d x}\right]=\frac{T_{b}-T_{w}}{d / 2}$. Rearranging,

$$
d=\sqrt{\frac{8 k_{g}\left(T_{b}-T_{w}\right)}{Q \frac{d \varepsilon}{d t}}} \text { or } \propto \sqrt{\frac{1}{\frac{d \varepsilon}{d t}}} .
$$

Deflagrations have the following dependence,

$$
\dot{m^{\prime \prime}}=\rho_{c} r_{b} \propto \sqrt{\alpha_{g} \frac{d \varepsilon}{d t}},
$$

where $r_{b}$ is the burn rate and $\alpha_{g}$ is the gas phase thermal diffusivity. Consequently,

$$
\frac{d \varepsilon}{d t} \propto r_{b}^{2},
$$

and then finally we find

$$
d \propto \sqrt{\frac{1}{d \varepsilon}} \propto \frac{1}{r_{b}} .
$$

Equation 9 shows that the critical diameter for combustion is inversely proportional to the burning rate. This model is consistent with the results of the capillary tube experiment and published data on the burning rates of the four HiN materials considered. Specifically, the burning rates of BTATz and DAATO3.5 are higher than TAGzT and much higher than DAAF at $1 \mathrm{~atm}[19,38]$.

Quenching in small channels for other materials has been studied previously, where it was shown that successful propagation could also depend on where the heat is released; specifically whether in the gas phase or near the surface [19]. To illustrate this concept, consider two limiting cases. First, consider a solid, which decomposes endothermically and all of the heat release is in the gas phase. If another burning surface is placed close to this burning surface, then the exothermic reaction in the gas phase could quench because the gas could be cooled because it is at a higher temperature than the surfaces. That cooling could quench the gas phase reactions, especially if 
they are strongly temperature dependent. This is the case considered in the above analysis. In contrast, consider a second case where all the heat release is in the condensed phase and the reaction is exothermic enough to self-propagate. Importantly, the gas produced from this reaction is at the final temperature and that gas temperature is equal to the surface temperature. If another identical burning surface were brought close to the original burning surface, there would be no change in the temperature at the surface or in the gas phase since the gas and surface temperature would be the same. Therefore, one would expect no effect with the width of the slot on a flame spreading into a slot with all condensed phase heat release. Thus, we argue that exothermic surface reactions are less sensitive to quenching in thin burning slots. Thus, it is possible that BTATz and DAATO3.5 did not quench because of their higher burning rates (above analysis) and in addition may also be due to significant near surface heat release. A similar observation has been made for nanoscale thermites in micro-channels that have significant condensed phase reactions and propagate well in microchannels [39]. When irradiated by the photoflash, it is likely that DAAF and TAGzT absorb similar amounts of visible light compared to BTATz but do not successfully ignite because of the failure of the initial reaction to propagate; that is, the reactions are quenched. Videos of the capillary tube experiment can be seen in the supplementary material.

\subsection{Laser Ignition of BTATz and DAATO3.5}

BTATz and DAATO3.5, being the only flash ignitable HiN materials, were further studied with $\mathrm{CO}_{2}$ laser heating. Table 3 summarizes tests performed with the laser. The range of laser irradiances reflect the span from the lowest to the highest irradiance during the entire study. It includes all laser ignition experiments performed, including those that did and did not ignite. As explained in the experimental methods section, the laser irradiance is carried by changing the focal distance to the sample and the laser power settings controlled through a LabVIEW program.

Table 3: Range and Number of Laser Experiments

\begin{tabular}{ccc}
\hline Material Tested & $\begin{array}{c}\text { Laser Irradiance } \\
\left(I_{\text {peak }}\right) \text { Range } \\
\mathrm{W} / \mathrm{cm}^{2}\end{array}$ & $\begin{array}{c}\text { Total Number of } \\
\text { Laser Tests }\end{array}$ \\
& & \\
\hline
\end{tabular}




\begin{tabular}{ccc}
\hline BTATz & $130-1580$ & 38 \\
DAATO3.5 & $410-1610$ & 24 \\
\hline
\end{tabular}

Similar to the flash tests, DAATO3.5 and BTATz showed significant gasification. This made the high speed schlieren videos the best tool to observe the onset and evolution of the gasification plume. The plume development observed was similar for both the flash and the laser. Figure 12 and Figure 13 show still images from the laser ignition. Videos of typical results can be seen in the supplemental material.
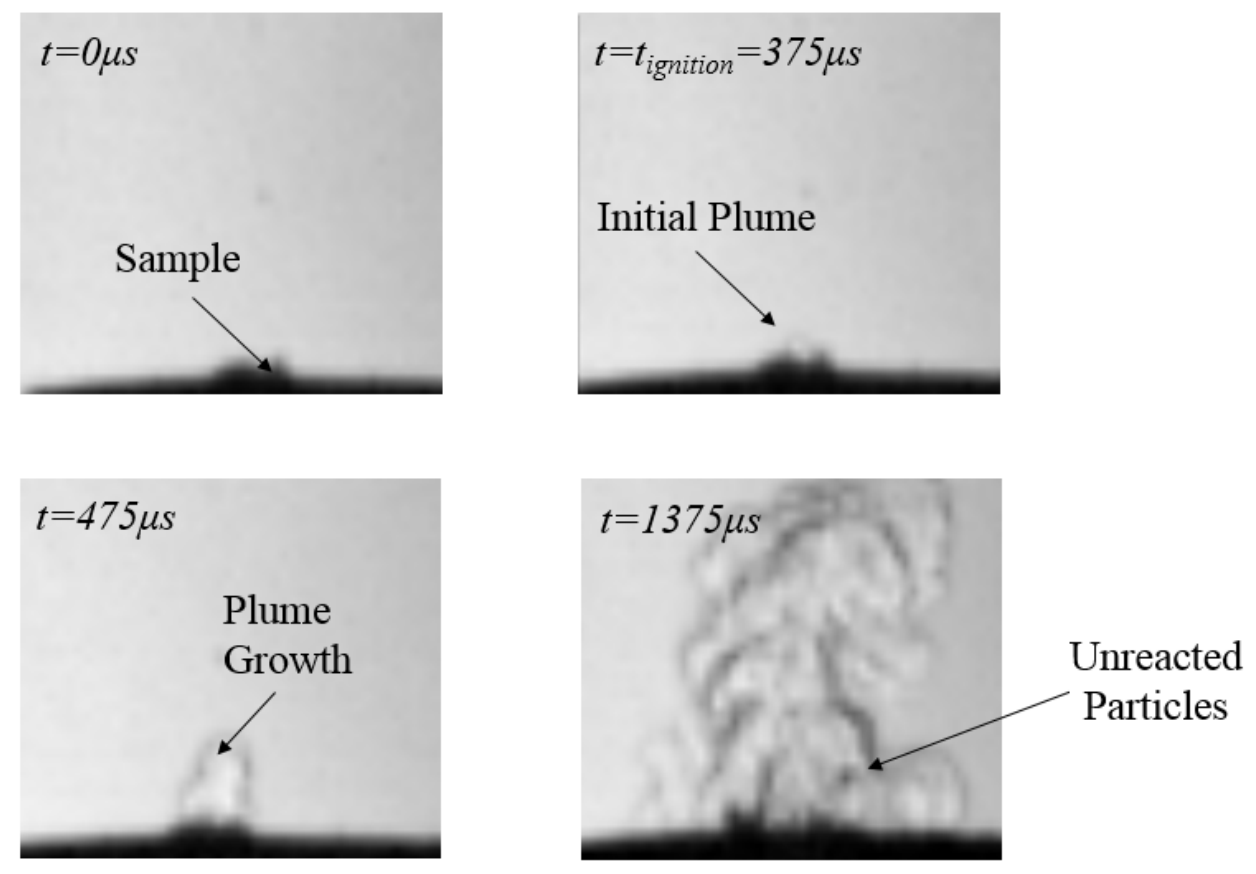

Figure 12: Schlieren sequence during laser ignition of BTATz $\left(I_{\text {peak }}=1283.9 \mathrm{~W} / \mathrm{cm}^{2}\right)$. 

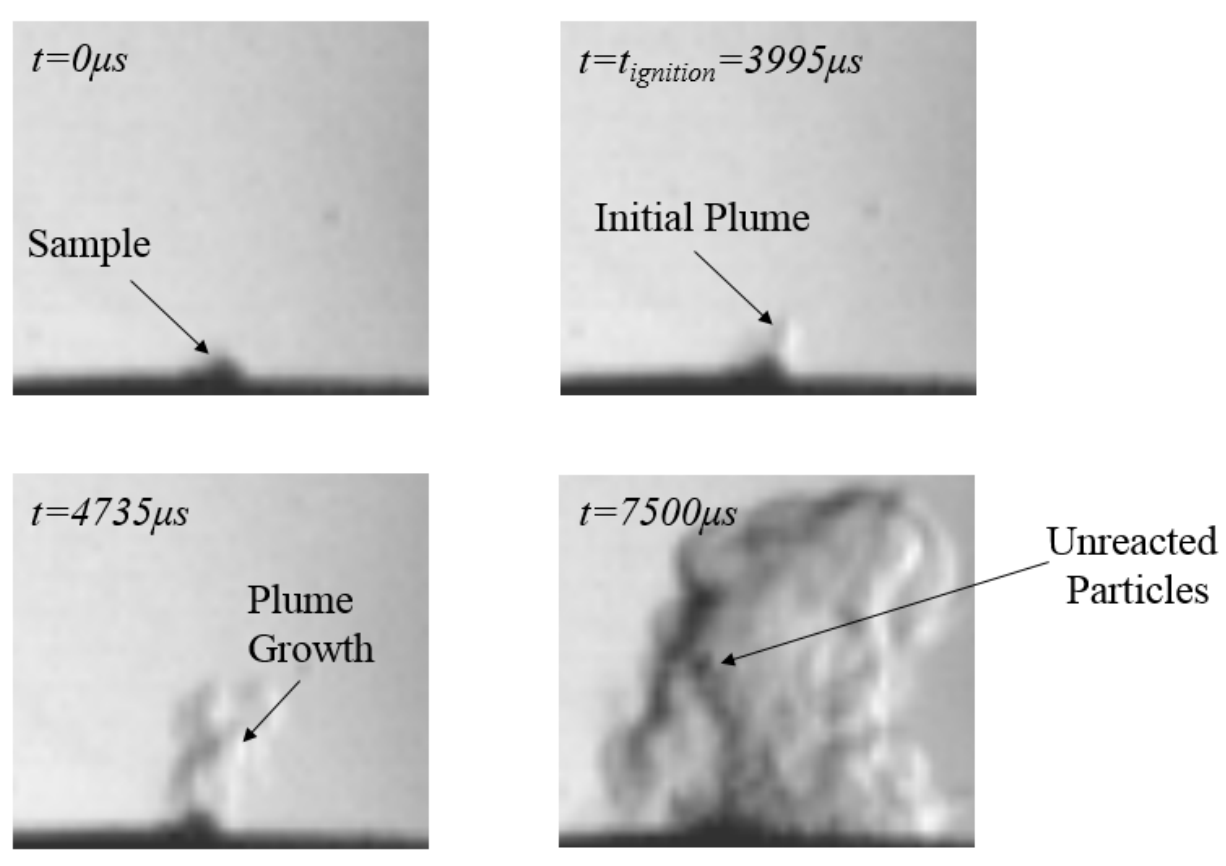

Figure 13: Schlieren sequence during laser ignition of DAATO3.5 $\left(I_{\text {peak }}=591.2 \mathrm{~W} / \mathrm{cm}^{2}\right)$.

\subsection{Comparison of Photoflash and Laser Irradiance and Energy}

Key parameters including ignition threshold, ignition delay, ignition energy, and peak irradiance for each ignition event were calculated and the results are presented in Figures 14 to 17. The peak irradiance is the maximum irradiance that exists spatially across the cross section of the beam. Because of the Gaussian profile, the peak irradiance is at the center of the beam. As presented in this data, the peak irradiance is also the maximum irradiance that exists spatially during the duration of the beam; that it is the highest irradiance achieved (spatially and temporally) for each test. It is important to note that the error bars presented take into account the scatter observed between each experiment and the experimental uncertainty. 


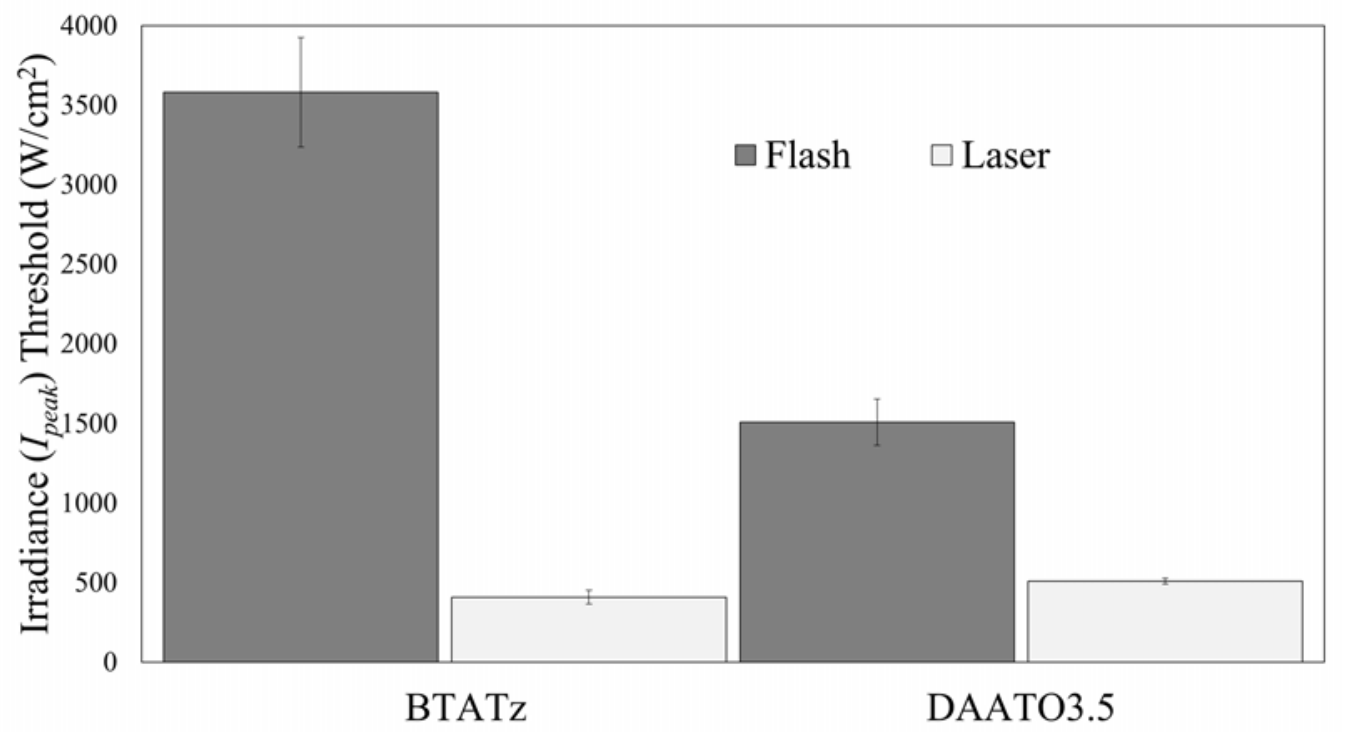

Figure 14: Peak irradiances at ignition thresholds.

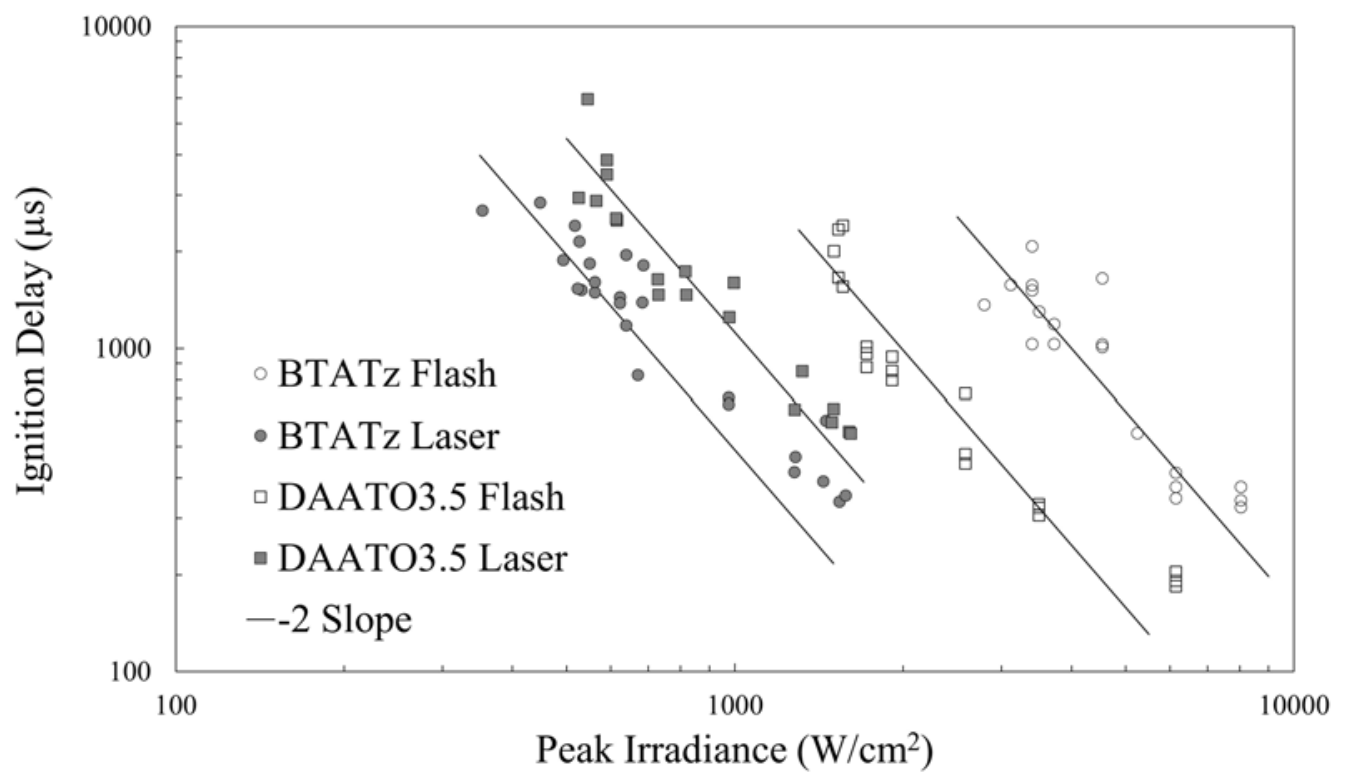

Figure 15: Ignition delay versus peak irradiance for all ignition experiments.

It is important to remember that the peak irradiance is the maximum irradiance achieved spatially and temporally during each test. For the laser, the peak irradiance is at the center and maximum at the start of the pulse while for the photoflash, the intensity is uniform spatially and maximum about $0.4 \mathrm{~ms}$ into the start of the pulse. Figure 14 compares the threshold peak irradiances for flash versus $\mathrm{CO}_{2}$ laser heating. The thresholds for flash ignition were significantly higher than 
those for the laser. This trend is also reflected in Figure 15, where the ignition delays are higher for the flash ignited samples at comparable peak irradiances to the laser ignited ones. Dark lines with slopes of -2 (corresponding to $t_{\text {ignition delay }} \propto q^{\prime \prime-2}$ ) are imposed on the data for comparison. For every specific ignition delay, a much lower laser $I_{\text {peak }}$ is needed to achieve ignition compared to the flash $I_{\text {peak }}$ required for ignition. This may indicate that only a fraction of the flash energy is absorbed, compared to the laser for which absorption in the far-IR is expected to be much higher.

Both the laser and flash pulses have finite, fixed durations. However, the ignition delay of each experiment varies. Hence, comparing each experiment by the peak irradiance (achieved at any location during the duration of the pulse) of the laser or flash pulse does not consider the amount of energy absorbed prior to ignition. To take this into account, the total energy per unit area irradiated prior to ignition (called the ignition energy) is calculated (using equation 2). Figure 16 shows the average of the ignition energy of the experiments at the threshold while Figure 17 compares the ignition delay to the ignition energy for all ignition experiments.

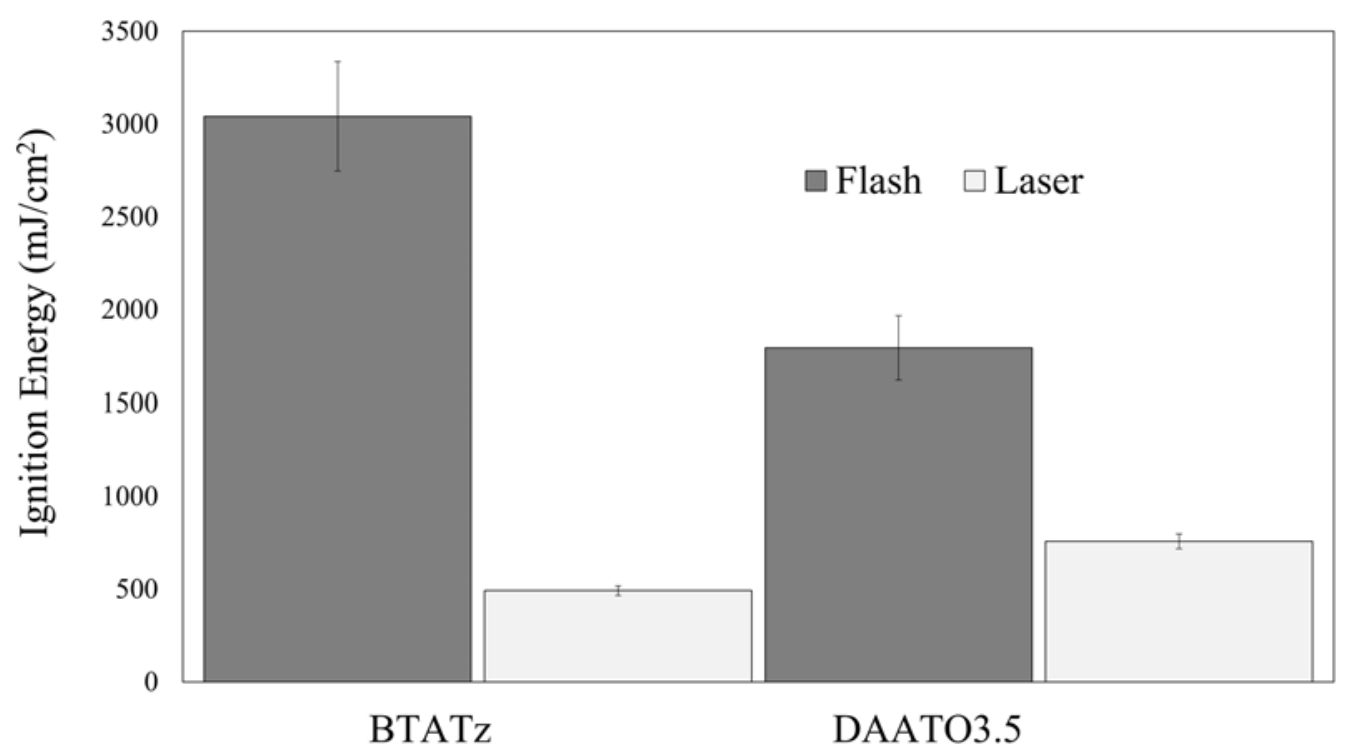

Figure 16: Ignition energies at thresholds. 


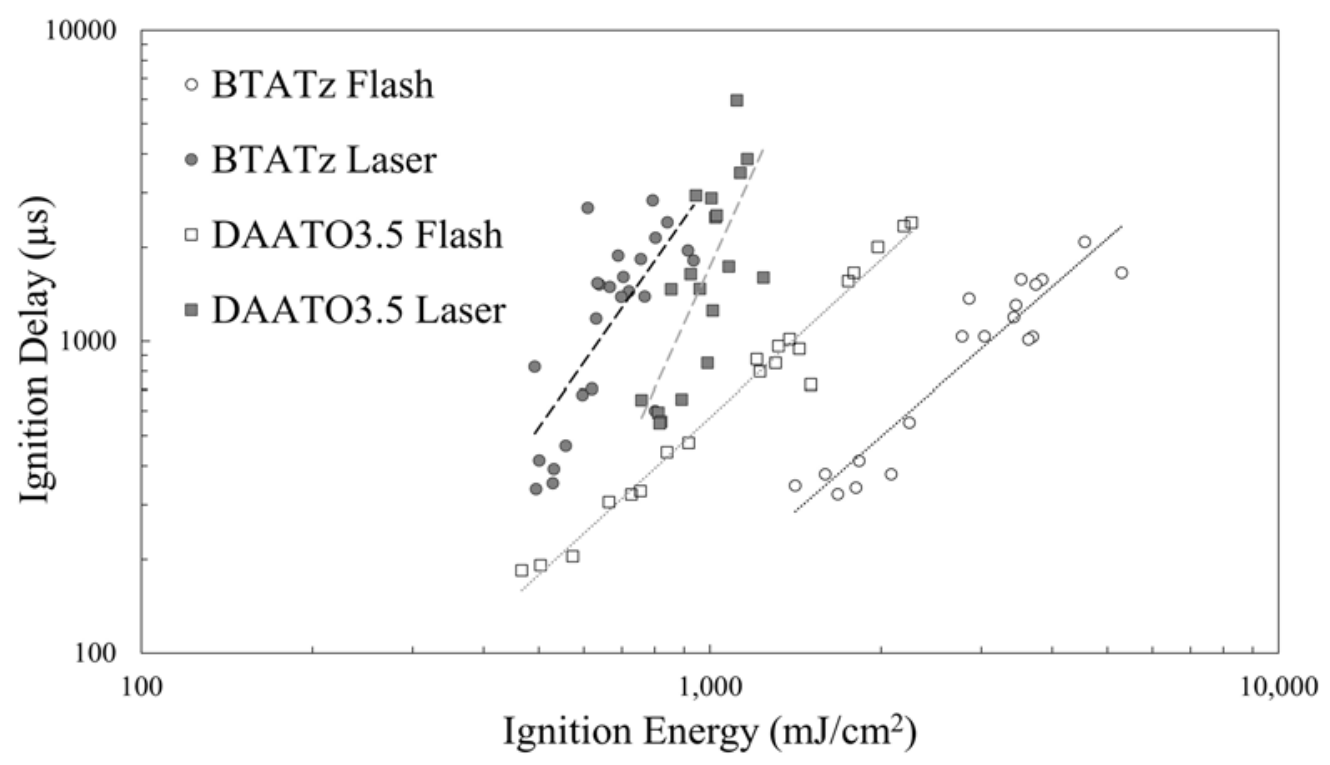

Figure 17: Ignition delay versus ignition energy for all ignition experiments.

Both DAATO3.5 and BTATz can clearly be ignited with a lower energy and irradiance using the $\mathrm{CO}_{2}$ laser than with the photoflash. In addition, for a given ignition delay, the peak laser irradiation and ignition energy required is a fraction of the flash ignition irradiance and ignition energy. An important and simple conclusion from these results is that the $\mathrm{CO}_{2}$ laser is a lot more effective than the photoflash in the ignition of $\mathrm{HiN}$ materials. The $\mathrm{CO}_{2}$ laser emits irradiation in the far-IR while the photoflash emits a broadband pulse that spans the visible and near IR range $[30,31,32]$. Although DAATO3.5 has a higher burning rate than BTATz, BTATz appears more sensitive to laser ignition that DAATO3.5. While it appears that BTATz is absorbing better when irradiated with the IR laser, we do not have enough information to conclude exactly what contributes to the lower ignition threshold of BTATz but can speculate that it likely relates to differences in optical properties.

As a comparison, the ignition thresholds of BTATz and DAATO3.5 are compared to those reported in earlier studies using primary explosives in Table 4. While this comparison compares HiN materials, which are secondary explosives, with that of flash ignitable primary explosives, it shows that the energy input required to remotely ignite HiN materials is comparable to that required to ignite at least some of the primary explosives. Comparing the laser ignition of BTATz and DAATO3.5, the ignition energy is almost as low as that of the electronic flash 
ignition of Nitrogen Iodide and Silver Nitride, both of which are very sensitive primary explosives. The IR laser is clearly very efficient in igniting these HiN materials.

Table 4: Comparison of ignition energy of HiN materials to that of primary explosives

\begin{tabular}{cc}
\hline Energetic Material & Ignition Energy $\left(\mathrm{J} / \mathrm{cm}^{2}\right.$ ) \\
\hline BTATz & $3000 \mathrm{~mJ} / \mathrm{cm}^{2}$ (photoflash), $490 \mathrm{~mJ} / \mathrm{cm}^{2}$ (IR laser) \\
DAATO3.5 & $1800 \mathrm{~mJ} / \mathrm{cm}^{2}$ (photoflash), $800 \mathrm{~mJ} / \mathrm{cm}^{2}$ (IR laser) \\
Nitrogen Iodide [3] & $160 \mathrm{~mJ} / \mathrm{cm}^{2}$ (from electronic flash, $0.8 \mathrm{~ms}$ duration) \\
Silver Nitride [3] & $200 \mathrm{~mJ} / \mathrm{cm}^{2}$ (from electronic flash,, $0.8 \mathrm{~ms}$ duration) \\
Silver Azide [3] & $2600 \mathrm{~mJ} / \mathrm{cm}^{2}$ (from electronic flash, $0.8 \mathrm{~ms}$ duration) \\
Lead Azide [3] & $2000 \mathrm{~mJ} / \mathrm{cm}^{2}$ (from electronic flash,0.8ms duration) \\
\hline
\end{tabular}

Observing the differences in laser and flash ignition characteristics in Figures 16 and 17, it may be assumed that only a fraction of the photoflash energy is absorbed by the HiN materials. This is evident from the higher photoflash threshold energies compared to the laser threshold energies. These HiN materials may be expected to absorb significantly more in the IR spectrum than in the visible spectrum and photochemical effects are not anticipated at the far-IR. Hence, we see no indication in our results of photochemical effects for these HiN materials.

Although the power fit in the log-log plot in Figure 15 may suggest the trend could be extrapolated to higher and lower irradiances, it is very likely that this trend will break down at some point. According to Ali et al., similar tests with $\mathrm{HMX}$ using a $\mathrm{CO}_{2}$ laser have shown a critical energy bottleneck such that higher irradiances will result in lower ignition delay but the ignition energy required will not drop below a critical energy level [40], and this could be explored with these materials in future work. Likewise, heat conduction and other losses will prevent ignition for low irradiances. It is also important not to drawn conclusions based on the DSC onset temperatures. Previous studies have shown that DSC onset temperatures do not 
corroborate well to ignition limits carried out at different heating rates, as certainly is the case in these experiments [41].

It is also worth noting from Figures 15 and 17 that a lower photoflash and laser energy is required to initiate ignition for those experiments at higher irradiances. For both the laser and flash ignition, the ignition energy is lower for higher irradiances, which also corresponds to short ignition delays. This could be because higher irradiances correspond to higher rates of heating which minimize heat losses. At higher irradiances, heat conduction through the sample and into the substrate is lower. Pulses with higher irradiance are more efficient as ignition can be achieved with less energy.

\section{Conclusion}

This work demonstrates, for the first time, that certain, non-primary explosive, HiN materials, specifically as BTATz and DAATO3.5, can be ignited using a xenon photoflash. Between these two HiN materials, DAATO3.5 is more sensitive to flash ignition than BTATz and this is likely due to its higher burning rate and its darker color, which leads to higher absorption of visible light from the photoflash. Although other HiN materials tested (DAAF, TKX-50 and TAG-ZT) did not ignite with the photoflash, it is still possible that they might ignite at different wavelengths not considered in this study.

Analysis of the flash and $\mathrm{CO}_{2}$ laser ignition experiments show that the ignition and energy thresholds observed in laser ignitions are a fraction of that of the photoflash. Hence, it is very likely these HiN materials absorb irradiation much better in the far-IR wavelengths in contrast to the broad flash spectrum spanning the visual and near-IR. Absorption leads to thermal heating, which leads to an exothermic decomposition of the HiN material. Although photochemical effects are possible, these effects are not clearly observed in this experiment. There could certainly be other HiN materials, not tested in this study, which respond well to other specific wavelengths, UV for instance.

Additionally, ignition of BTATz and DAATO3.5 are shown to follow a trend that indicates that higher irradiances require less energy to initiate ignition. This is due to lower heat losses (less 
time for heat transfer) within the duration of the laser or flash pulse before ignition. This trend will likely break down at some point, but higher fluxes would need to be considered. BTATz is shown to be more sensitive to the IR laser considered here than DAATO3.5. There is not enough information to make a conclusion solely based on this study as to why this trend is observed, but we speculate that it is likely related to optical absorption differences.

In contrast, TKX-50, DAAF and TAGzT did not flash ignite. It is assumed that TKX-50 did not flash ignite because it is a white transparent crystal powder and scatters incident visible light. Further ignition tests with the capillary tubes were carried out on BTATz, DAATO3.5, DAAF and TAGzT to compare the ability of HiN materials to propagate a reaction through a small channel. During the microchannel combustion experiment, BTATz and DAATO3.5 were observed to successfully propagate down small channels, in contrast to DAAF and TAGzT that rapidly quenched in the tube.

Upon irradiation, these HiN materials absorb energy, and reaction begins as microscopic hot sites. However, the observed differences are attributable to their reaction characteristics. We saw a correlation to successful microchannel combustion. Based on the capillary tube studies, it is likely that BTATz and DAATO3.5 are sensitive to flash ignition because of their higher burning rates and because much of their chemical energy is released at the surface region during decomposition rather than in gas phase oxidation reactions. A simple analysis is used to show how the critical diameter is inversely proportional to the burning or deflagration rate. Also, because propagation in small channels depends on chemical heat release overcoming heat losses to channel walls, exothermic decomposition reactions at or near the surface as opposed to gas phase oxidation favor microchannel combustion since that would minimize the time for heat loss to the walls in the flame.

Due to their unique photoactivity, reactivity, and acceptable sensitivity, BTATz and DAATO3.5 could be engineered for use as energetic materials in remote/non-contact ignition mechanisms. This study shows that a high powered short pulse of infrared light is more efficient than using a broadband photoflash to ignite these HiN materials. Compacts of BTATz and DAATO3.5 may be remotely ignited and a sustained combustion can occur. With additional research into 
implementing this technology, BTATz and DAATO3.5 have the potential to be used in gas generators, micro-thrusters and micro-actuators in micro-electro-mechanical systems (MEMS).

\section{References}

[1] F. P. Bowden, A. D. Yoffee, Initiation and Growth of Explosions in Liquids and Solids, Cambridge University Press, U.K, 1952. 88-112.

[2] M.R. Manaa, A.R. Mitchell, P.G. Garza, P.F. Pagoria, B.E. Watkins, Flash Ignition and Initiation of Explosives-Nanotubes Mixture, J. Am. Chem. Soc. 127 (2005) 13786-13787. doi:10.1021/ja0547127.

[3] J. Eggert, The Ignition of Explosives by Radiation, J. Phys. Chem. 63 (1959) 11-15. http://pubs.acs.org/doi/abs/10.1021/j150571a005.

[4] L.S. Nelson, J.L. Lundberg, Flash Initiation of Thermal Reactions, Heterog. Flash Initiat. Therm. React. 63 (1959) 433-436.

[5] X. Xiang, S. Xiang, Z. Wang, X. Wang, G. Hua, Photo-Responsive Behaviors and Structural Evolution of Carbon-Nanotube-Supported Energetic Materials Under a Photoflash, Mater. Lett. 88 (2012) 27-29. doi:10.1016/j.matlet.2012.08.049.

[6] P.M. Ajayan, M. Terrones, A. De Guardia, V. Huc, N. Grobert, B.Q. Wei, et al., Nanotubes in a Flash — Ignition and Reconstruction, Science. 296 (2002) 705. doi:10.1126/science.296.5568.705.

[7] S.H. Tseng, N.H. Tai, W.K. Hsu, L.J. Chen, J.H. Wang, C.C. Chiu, et al., Ignition of Carbon Nanotubes Using a Photoflash, Carbon N. Y. $45 \quad$ (2007) 958-964. doi:10.1016/j.carbon.2006.12.033.

[8] N. Braidy, G.A. Botton, A. Adronov, Oxidation of Fe Nanoparticles Embedded in SingleWalled Carbon Nanotubes by Exposure to a Bright Flash of White Light, Nano Lett. 2 (2002) 1277-1280. doi:10.1021/n1025718m.

[9] A.M. Berkowitz, M.A. Oehlschlaeger, The Photo-Induced Ignition of Quiescent Ethylene/Air Mixtures Containing Suspended Carbon Nanotubes, Proc. Combust. Inst. 33 (2011) 3359-3366. doi:10.1016/j.proci.2010.07.013. 
[10] T.R. Sippel, S.F. Son, L.J. Groven, Modifying Aluminum Reactivity with Poly(Carbon Monofluoride) via Mechanical Activation, Propellants, Explos. Pyrotech. 38 (2013) 321-326. doi:10.1002/prep.201200202.

[11] P. V. Kamat, Photophysical, Photochemical and Photocatalytic Aspects of Metal Nanoparticles, J. Phys. Chem. B. 106 (2002) 7729-7744. doi:10.1021/jp0209289.

[12] J. M. Zucker, B. C. Tappan, D. M. Oschwald, D. N. Preston, N. J. Burnside, Characterization of Energetic Formulations Optimized for Optical Initiation Proc. 12th Int. Symp. Detonation, Coeur d'Alene, Idaho, April 11-16, (2010) 724.

[13] J.S. Courtney-Pratt, G.T. Rogers, Initiation of Explosion by Light and by Flying Fragments, Nature. 175 (1955) 632-633.

[14] J.E. Abboud, X. Chong, M. Zhang, Z. Zhang, N. Jiang, S. Roy, et al., Photothermally Activated Motion and Ignition Using Aluminum Nanoparticles, Appl. Phys. Lett. 102 (2013) 023905. doi:10.1063/1.4776660.

[15] M.T. Greenfield, S.D. McGrane, C. a. Bolme, J. a. Bjorgaard, T.R. Nelson, S. Tretiak, et al., Photoactive High Explosives: Linear and Nonlinear Photochemistry of Petrin Tetrazine Chloride, J. Phys. Chem. A. (2015) 150507163117005. doi:10.1021/acs.jpca.5b02092.

[16] L.J. Cote, R. Cruz-Silva, J. Huang, Flash Reduction and Patterning of Graphite Oxide and its Polymer Composite, J. Am. Chem. Soc. 131 (2009) 11027-11032.

[17] D.E. Chavez, M.A. Hiskey, R.D. Gilardi, 3,3'-Azobis(6-amino-1,2,4,5-tetrazine): A Novel High-Nitrogen Energetic Material Angew. Chem., 112 (2000) 1861.

[18] A.N. Ali, M.M. Sandstrom, D.M. Oschwald, K.M. Moore, S.F. Son, Laser Ignition of DAAF, DHT and DAATO3.5, Propellants, Explos. Pyrotech. 30 (2005) 351-355. doi:10.1002/prep.200500025.

[19] B.C. Tappan, A.N. Ali, S.F. Son, T.B. Brill, Decomposition and Ignition of the HighNitrogen Compound Triaminoguanidinium Azotetrazolate (TAGzT), Propellants, Explos., Pyrotech. 31 (2006) 163-168. doi:10.1002/prep.200600023.

[20] E.G. Francois, D.E. Chavez, M.M. Sandstrom, The Development of a New Synthesis Process for 3,3'-Diamino-4,4'-azoxyfurazan (DAAF), Propellants, Explos. Pyrotech. 35 (2010) 529-534. doi:10.1002/prep.200900045.

[21] D.E. Chavez, M.A. Hiskey, R.D. Gilardi, Novel High-Nitrogen Materials Based on Nitroguanyl-Substituted Tetrazines, (2004) 20-22. 
[22] A. N. Ali, S.F. Son, M. a. Hiskey, D.L. Naud, Novel High Nitrogen Propellant Use in Solid Fuel Micropropulsion, J. Propuls. Power. 20 (2004) 120-126. doi:10.2514/1.9238.

[23] T.M. Klapötke, New Nitrogen-Rich High Explosives, Struct Bond (2007) 125: 85-121 doi: 10.1007/430_2007_057.

[24] G. Steinhauser, T.M. Klapötke, “Green” Pyrotechnics: A Chemists' Challenge, Angew. Chemie Int. Ed. 47 (2008) 3330-3347. doi:10.1002/anie.200704510.

[25] R. Sivabalan, M. Anniyappan, S.J. Pawar, M.B. Talawar, G.M. Gore, S. Venugopalan, et al., Synthesis, Characterization and Thermolysis Studies on Triazole and Tetrazole Based High Nitrogen Content High Energy Materials, J. Hazard. Mater. 137 (2006) 672-680. doi:10.1016/j.jhazmat.2006.03.038.

[26] J. Oxley, Thermal Decomposition of High-Nitrogen Energetic Compounds-DihydrazidoS-Tetrazine Salts, Thermochim. Acta. 384 (2002) 91-99. doi:10.1016/S0040-6031(01)00780-8.

[27] A. Bhattacharya, Y.Q. Guo, E.R. Bernstein, Unimolecular decomposition of tetrazine-NOxide Based High Nitrogen Content Energetic Materials From Excited Electronic States., J. Chem. Phys. 131 (2009) 194304. doi:10.1063/1.3262688.

[28] J.R. Enerson, P. Richey, J.H. Lucius, Apparatus and Method for Using Tetrazine-Based Energetic Material. U.S Patent 20090301601. 10 ${ }^{\text {th }}$ Dec 2009.

[29] C. Rossi, K. Zhang, D. Estève, P. Alphonse, P. Tailhades, C. Vahlas, Nanoenergetic Materials for MEMS: A review, J. Microelectromechanical Syst. 16 (2007) 919-931. doi:10.1109/JMEMS.2007.893519.

[30] T. Roth, J. Hohl-Ebinger, E. Schmich, W. Warta, S.W. Glunz, R.A. Sinton, Improving the Accuracy of Suns-Voc Measurements Using Spectral Mismatch Correction, 33rd IEEE Photovolatic Spec. Conf. (2008) 1-5. doi:10.1109/PVSC.2008.4922686.

[31] P. Rosenits, T. Roth, W. Warta, S.W. Glunz, Influence of Different Excitation Spectra on the Measured Carrier Lifetimes in Quasi-Steady-State Photoconductance Measurements, Sol. Energy Mater. Sol. Cells. 94 (2010) 767-773. doi:10.1016/j.solmat.2009.12.022.

[32] Y. Ohkura, P.M. Rao, X. Zheng, Flash ignition of Al nanoparticles: Mechanism and applications, Combust. Flame. 158 (2011) 2544-2548. doi:10.1016/j.combustflame.2011.05.012.

[33] H.K. Aslin, Measurement of Radiant Energy Emitted by Xenon Flashlamps, Rev. Sci. Instrum. 38 (1967) 377. doi:10.1063/1.1720709. 
[34] A.S. Tappan, A.M. Renlund, G.T. Long, S.H. Kravitz, K.L. Erickson, W.M. Trott, et al., Microenergetic Processing and Testing to Determine Energetic Material Properties at the Mesoscale, Proc. 12th Int. Symp. Detonation, San Diego, USA. (2002). http://intdetsymp.org/detsymp2002/PaperSubmit/FinalManuscript/pdf/Tappan-135.pdf.

[35] B.C. Tappan, J.M. Lloyd and V.E. Sanders, On The Shock Insensitivity of Triaminoguanidinium Azotetrazolate (TAGzT), Report No. LA-UR 09-07969, Los Alamos National Laboratories, Los Alamos, NM, USA, 2009.

[36] S. Depiero, J. Koerner, J. Maienschein, R. Weese, Small-Scale Safety and Thermal Characterization of 3,3'-diamino-4,4'-azoxyfurazan (DAAF), Report No. UCRL-TR-231649, Lawrence Livermore National Laboratories, Livermore, CA, USA, 2007.

[37] N. Fischer, D. Fischer, T.M. Klapötke, D.G. Piercey, J. Stierstorfer, Pushing the Limits of Energetic Materials - the Synthesis and Characterization of Dihydroxylammonium 5,5'bistetrazole-1,1'-diolate, J. Mater. Chem. 22 (2012) 20418. doi:10.1039/c2jm33646d.

[38] S.F. Son, H.L. Berghout, C.A. Bolme, D.E. Chavez, D. Naud, M.A. Hiskey, Burn Rate Measurements of HMX, TATB, DHT, DAAF, and BTATz, Proc. Combust. Inst. 28 (2000) 919924. doi:10.1016/S0082-0784(00)80298-2.

[39] S.F. Son, B.W. Asay, T.J. Foley, R. a. Yetter, M.H. Wu, G. a. Risha, Combustion of Nanoscale Al/MoO3 Thermite in Microchannels, J. Propuls. Power. 23 (2007) 715-721. doi:10.2514/1.26090.

[40] A.N. Ali, S.F. Son, B.W. Asay, M.E. Decroix, M.Q. Brewster, High-Irradiance Laser Ignition of Explosives, Combust. Sci. Technol. $175 \quad$ (2003) 1551-1571. doi:10.1080/00102200302358.

[41] N. W. Piekiel, R. E. Cavicchi, M. R. Zachariah, Rapid-Heating of Energetic Materials Using a Micro-Differential Scanning Calorimeter, Thermochimica Acta, 521 (2011) 125-129. doi:10.1016/j.tca.2011.04.015 


\section{Acknowledgement}

The authors will like to acknowledge the M-7 research group at Los Alamos for providing the laser and high speed imaging equipment for the capillary tube experiments. The Los Alamos National Laboratory is operated by Los Alamos National Security for the U. S. Department of Energy’s National Nuclear Security Agency under contract DE-AC52-06NA25396. 